\title{
Minimally invasive endoscopic technique of harvesting free gracilis muscle flap to lower donor site morbidity: A feasibility study in cadavers
}

\author{
Jamal A Mohammad MD FRCSC, Saleh M Shenaq MD \\ Division of Plastic Surgery, Baylor College of Medicine, Houston, Texas, USA
}

\begin{abstract}
JA Mohammad, SM Shenaq. Minimally invasive endoscopic technique of harvesting free gracilis muscle flap to lower donor site morbidity: A feasibility study in cadavers. Can J Plast Surg 1999;7(2):81-85.

Endoscopic mobilization and harvesting of the gracilis muscle for free transfer applications and the versatility of this method are discussed in this report. This procedure was performed in 12 fresh human cadaver limbs (from six cadavers) to master the surgical technique for future clinical applications. Through two separate $2 \mathrm{~cm}$ incisions, one placed proximally and one distally along the axis of the muscle, the endoscope allowed the gracilis muscle and its related anatomical structures to be viewed, particularly the dominant vascular pedicle. The muscle flap, along with its vascular pedicle and motor nerve, were successfully harvested with the aid of endoscopy. The potential clinical advantages of endoscopically harvesting the gracilis muscle flap include shortening of the size of the surgical scar, relief of postoperative pain and hastened recovery of function.
\end{abstract}

Key Words: Endoscopic plastic surgery; Gracilis muscle flap; Free muscle transfer

Technique endoscopique peu effractive pour le prélèvement d'un lambeau libre de muscle droit interne de la cuisse pour réduire la morbidité au site du prélèvement : une étude de faisabilité sur des cadavres

\begin{abstract}
RÉSUMÉ : La mobilisation et le prélèvement endoscopique du muscle droit interne de la cuisse pour des applications de transferts libres et la versatilité de cette méthode sont discutées dans le présent article. Nous avons pratiqué cette intervention sur 12 membres frais de cadavres humains (six cadavres) afin de maîtriser la technique chirurgicale pour des applications cliniques futures. Par le biais de deux incisions distinctes de $2 \mathrm{~cm}$, une proximale et une distale, le long de l'axe du muscle, on a pu, à l'aide de l'endoscope, observer le muscle droit interne de la cuisse et ses structures anatomiques connexes, en particulier le pédicule vasculaire dominant. Le lambeau musculaire accompagné de son pédicule vasculaire et de son nerf moteur ont été prélevés par endoscopie avec succès. Les avantages cliniques potentiels du prélèvement endoscopique d'un lambeau de muscle droit interne de la cuisse comprennent : une réduction de la taille de la cicatrice chirurgicale, le soulagement de la douleur postopératoire et une
\end{abstract} récupération accélérée de la fonction.

$\mathrm{T}$ he gracilis muscle flap has several applications in reconstructive plastic surgery. The wide clinical application of this flap is due to its reliable neurovascular pedicle, its long, narrow configuration and its ability to leave minimal functional deficit. The gracilis flap is the first flap to be transferred as a free muscle flap (1). The gracilis muscle is an excellent source for filling small- and medium-sized soft tissue defects, especially in the lower extremity (2-6). It has also

Correspondence and reprints: Dr Saleh M Shenaq, Division of Plastic Surgery, Baylor College of Medicine, 6560 Fannin, Suite 800, Houston, Texas 77030, USA. Telephone 713-798-6310, fax 713-798-3806,

e-mailsshenaq@bcm.tmc.edu been used to restore the loss of muscle function in facial paralysis (7-9), and in the replacement of flexor and extensor muscle loss of the forearm, anterior compartment of the upper arm and anterior compartment of the lower leg (10). The gracilis muscle flap can also be used as a musculocutaneous free flap whenever skin coverage is required $(4,11)$. Despite the good clinical outcome of these microsurgical reconstructions, the donor site is frequently a source of morbidity, including scar deformity and reduced mobility, and a significant contributor to increased recovery time after surgery $(12,13)$. Following traditional surgical approaches to harvesting the gracilis muscle, the presence of a long and cosmetically unacceptable scar at the donor site may affect 


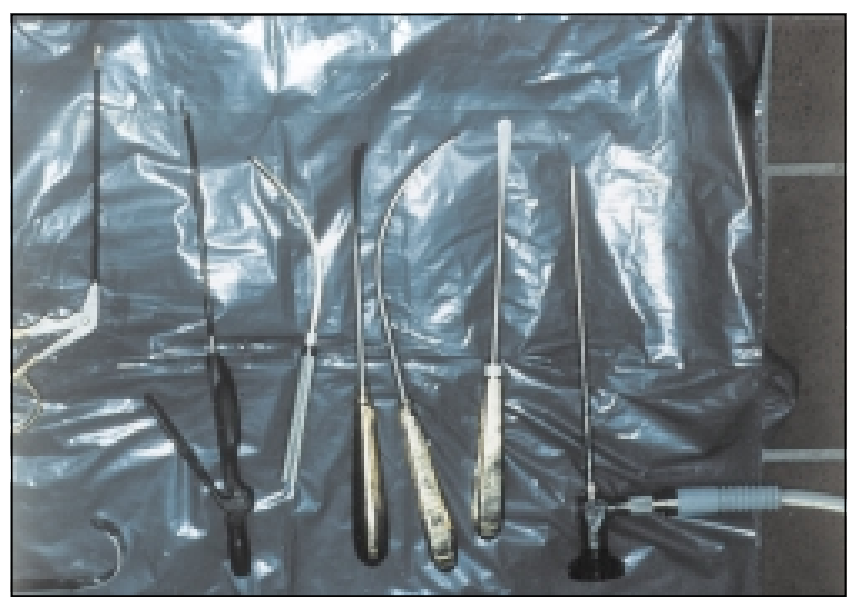

Figure 1) Snowden-Pencer endoscopic setup (Snowden-Pencer Corp, Georgia) used in this study

the final outcome of this surgical procedure. Harvesting the gracilis muscle through the use of techniques yielding less donor site morbidity would, therefore, be advantageous.

Minimal access surgery using endoscopic techniques has identified new applications in various reconstructive surgical fields in recent years. Endoscopic surgery offers many advantages over previous open techniques such as shorter skin incisions, magnified surgical field and structures, less scarring and more rapid recovery time $(14,15)$. Because endoscopic surgery can be performed with a high level of success, this technique is employed extensively for various kinds of flap harvest, such as omentum (16), jejunum $(16,17)$, rectus abdominis muscle (18), latismus dorsi muscle (19) and tensor fascia late muscle (20). In a recent clinical study, endoscopic harvest of free gracilis muscle flap produced good clinical results in reinnervation procedures, resulting in shorter skin incisions and decreased scar formation.

In the present study, the gracilis muscle was harvested with the aid of the endoscope. The main purpose of this procedure for future clinical application is to minimize the resulting scar, to lessen postoperative discomfort and to hasten recovery time.

\section{SURGICAL ANATOMY}

Many studies have described the anatomy of the gracilis muscle and its surgical landmarks for proper identification and harvesting $(4,11,21-25)$. The gracilis muscle is the most medial muscle in the thigh. It can be easily located and palpated by extending the knee and abducting the externally rotated hip. It assists in abduction of the lower extremity and flexion of the knee and hip joints.

The gracilis muscle originates from the pubic tubercle and the inferior ramus of the pubis. The proximal portion of the muscle has a strap configuration and the distal portion has a pennate configuration. It passes distally between the adductor longus and adductor magnus muscles, and tapers to a long, thin tendinous part between the sartorius and

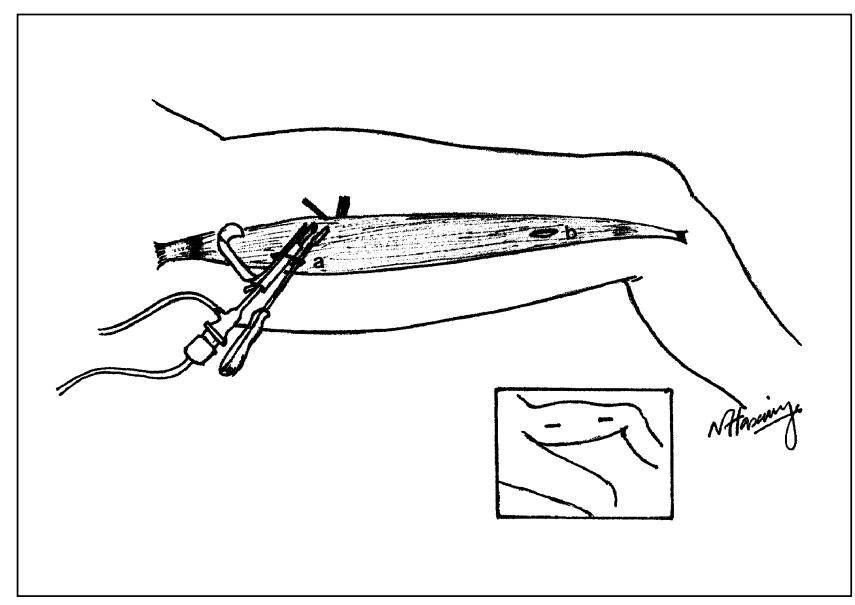

Figure 2) Location of the two skin incisions $(a, b)$. Each incision allows the placement of the endoscope and another instrument. The assistant can use another instrument in the other incision for surgical assistance during the endoscopic dissection procedure

semitendinosus muscles, medial to the condyle of the femur, to insert in the tibia below its tibial tubercle. The average length of the muscle is 25 to $30 \mathrm{~cm}$ with an additional 10 to $12 \mathrm{~cm}$ of tendon.

The blood supply to the gracilis muscle is dependent on two to three vascular pedicles, the proximal pedicle being dominant. The proximal arterial blood supply, the medial circumflex femoral artery, originates from the profunda femoris artery. It enters the muscle approximately 8 to $10 \mathrm{~cm}$ below the inguinal ligament. The artery is 1 to $2 \mathrm{~mm}$ in diameter with two venae comitantes. When the vascular pedicle is dissected more proximally to its origin, an approximate length of 5 to $8 \mathrm{~cm}$ can be obtained. Numerous musculocutaneous vessels are present in the proximal third of the muscle. When a musculocutaneous flap is desired, a skin paddle can be designed along the long axis of the muscle. The two minor distal vascular pedicles originate from the superficial femoral vessels and enter the distal third of the muscle.

Motor innervation to the muscle is via a single branch of the obturator nerve. This motor branch is composed of two to six fascicles and enters the muscle obliquely just proximal to the medial circumflex vascular pedicle.

\section{MATERIALS AND METHODS}

Six fresh human cadaver limbs were used for this study. Twelve free gracilis flaps were harvested with the aid of the endoscope. This study was conducted at the anatomy laboratory of Baylor College of Medicine, Houston, Texas. Adequate knowledge of the surgical anatomy of the gracilis muscle and its related structures was achieved through previous anatomical studies in preserved and fresh human cadavers.

\section{Instruments}

The Snowden-Pencer endoplastic endoscopic setup (Snowden-Pencer Corp, Georgia) was used for this study (Figure 1). This setup included a $4 \mathrm{~mm}$ rigid endoscope with 

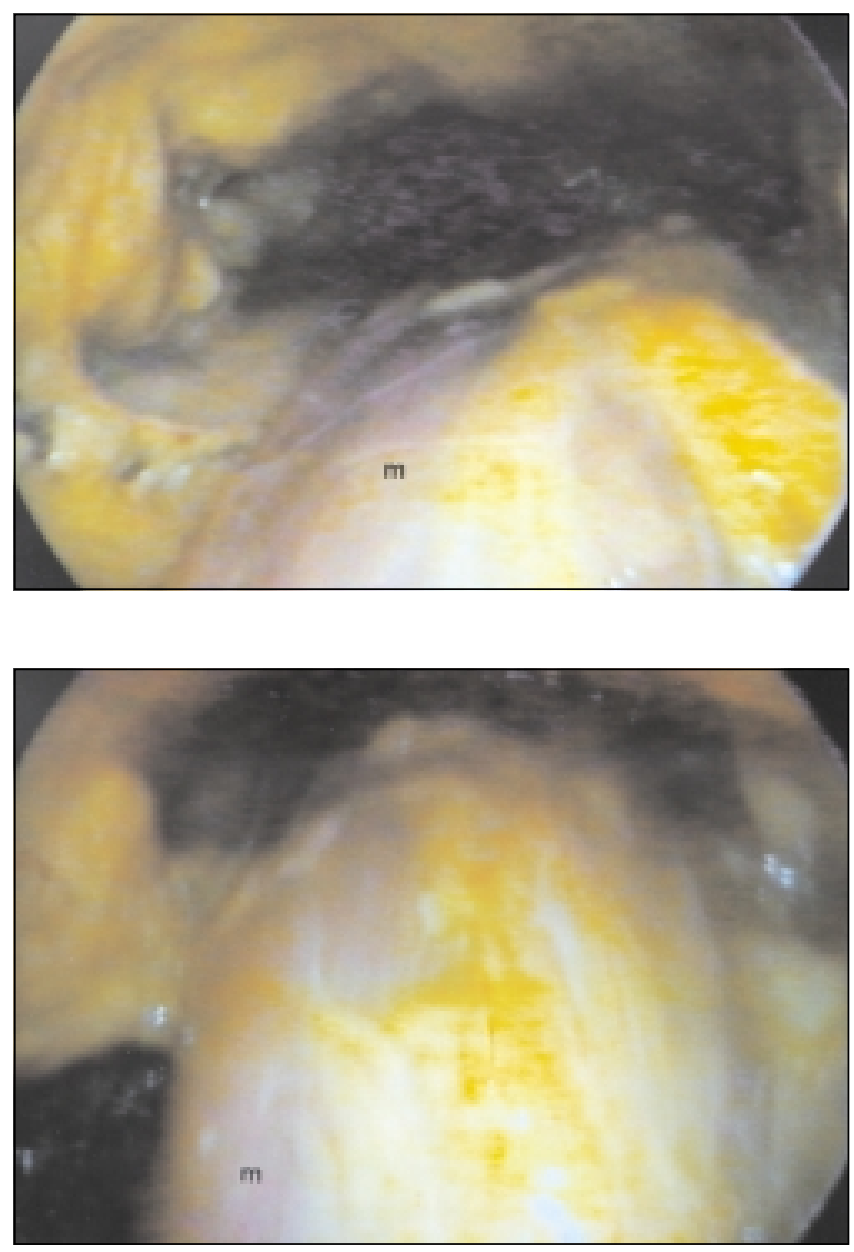

Figure 3) Top and Bottom Anterior surface of the gracilis muscle (m) as viewed through the distal skin incision

a $30^{\circ}$ angle lens. In addition to the regular surgical instruments, traditional endoscopic surgical tools that were used included elevators, dissectors, scissors, nerve protectors and retractors. Endoscopic surgery is performed while viewing the images on a television monitor and is recorded by a video cassette recorder.

\section{Incisions}

The leg was abducted and externally rotated with the knee flexed. Palpation of the gracilis muscle confirmed its location at the medial aspect of the thigh (Figure 2). It lies posterior to a line that is drawn from the adductor tendon to the tibial tubercle. Two skin incisions $4 \mathrm{~cm}$ in length were placed proximally and distally over the anatomical course of the muscle.

The proximal incision was made $8 \mathrm{~cm}$ from the pubic tubercle and the distal incision $5 \mathrm{~cm}$ to the muscle insertion. After the incision was made, sharp dissection was performed to separate the surrounding subcutaneous tissues from the muscle. Dissection was performed to the extent possible under direct visualization to create an optical cavity for the endoscope.
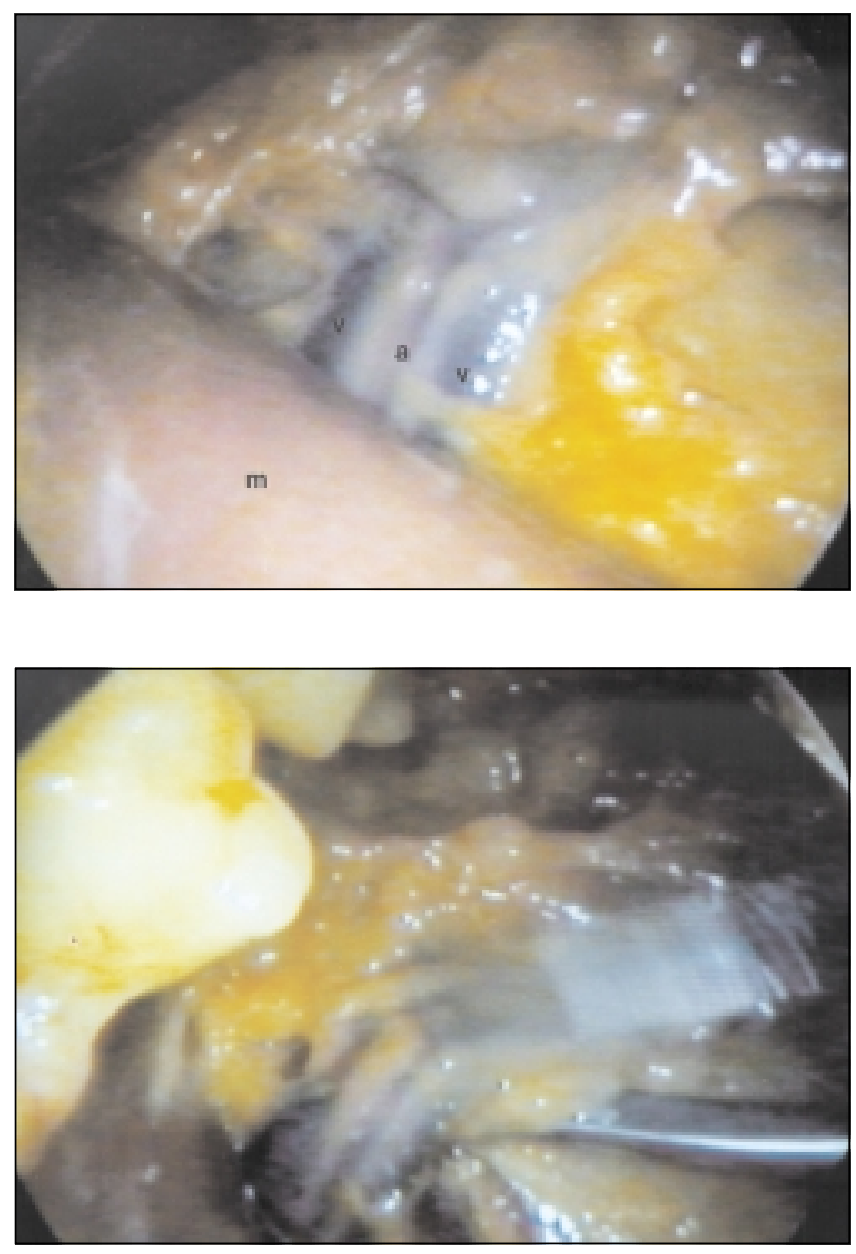

Figure 4) Top Endoscopic view of the major vascular pedicle of the muscle $(m)$, the main artery $(a)$ and two venae comitantes $(v)$. Bottom Endoscopic manipulation of the pedicle

\section{Endoscopic approach}

The endoscope was inserted through its sleeve retractor in one incision to clear and identify the anterior and posterior borders of the muscle (Figure 3 ). The endoscope allows magnification and manipulation of the gracilis muscle and its related anatomical structures while observing the procedure on a wide view television monitor. The surgeon can hold the endoscope in one hand and an endoscopic instrument for dissection in the other; together, both are inserted through the same skin incision. After proximal dissection of the muscle was completed, the endoscope was removed and inserted through the distal incision. The posterior surface of the muscle was easily accessible to endoscopic dissection. The multiple minor vascular pedicles were visualized and ligated under magnification. The endoscopic dissection of the proximal vascular pedicle was performed meticulously to avoid accidental damage of the pedicle. The pedicle was disected while the assistant retracted the adductor muscle mass away from the gracilis muscle in order to display the vascular pedicle to the surgeon (Figure 4). Dissection of the pedicle towards its origin from the profunda femoris is recommended. The vascular 


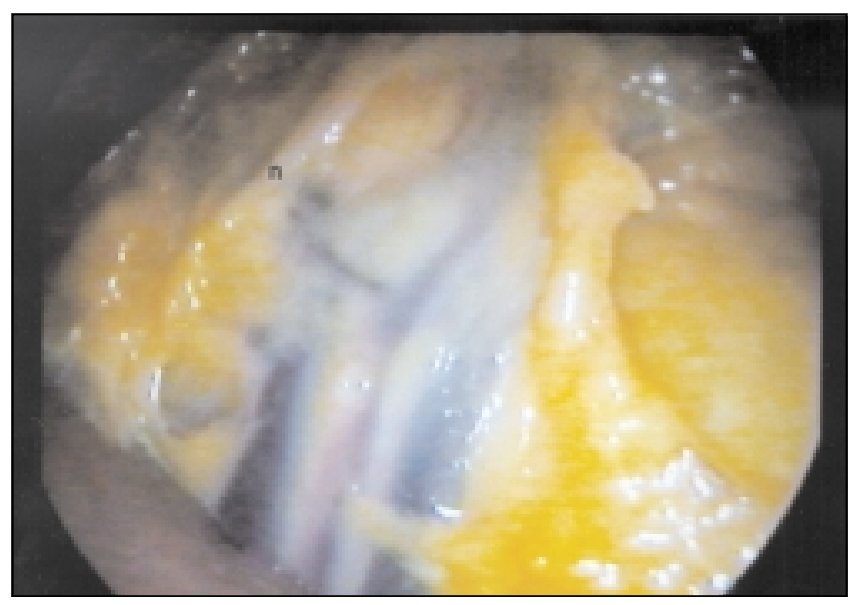

Figure 5) Motor branch of the gracilis muscle (n) courses obliquely to the vascular pedicle

pedicle can easily be identified 8 to $12 \mathrm{~cm}$ from the muscle origin. A $5 \mathrm{~cm}$ length of pedicle can be developed.

Further proximal dissection identified the motor branch of the obturator nerve (Figure 5) as it passes obliquely to the proximal vascular pedicle. Before clamping the pedicle, dissection was continued proximally and distally, and the muscle was completely separated from its bed. The tendinous part of the muscle should be divided first and the origin second. At this stage, the vascular pedicle was clamped and the nerve was divided. The muscle can be retrieved from the incision and be readily available for transfer (Figure 6).

\section{SUMMARY}

The gracilis muscle is easily accessible in the medial thigh region. The free gracilis flap is well established as an excellent reconstructive tool in both restoration of muscle function and soft tissue coverage in reconstructive surgical procedures.

This technique developed for endoscopic gracilis harvest has several unique features. Extensive skin incision is avoided, magnification of visualization of the anatomical structures is improved, thus avoiding inadvertent injury, and faster dissection of the undersurface of the muscle and maximal muscle length is obtained through two short skin incisions. The dominant vascular pedicle of the gracilis muscle is dissected under direct vision, which allows complete identification and preservation early in the procedure. With this technique, no balloon dissector or special lifting instrument is required to undermine the gracilis muscle because it is easily undermined with the aid of regular straight and curved endoscopic elevators. It also provides superior illumination and visualization of the anatomical structures being dissected. Thigh scars are much shorter after gracilis free flap harvesting than the scars following the conventional open technique. However, this procedure may have some limitations. Endoscopic harvesting is tedious and time consuming, bleeding occurring during dissection may present a problem in live experimental subjects, and the cost of the endoscopic setup and instruments is high. It is our contention that reconstructive surgeons can take advantage of minimally invasive endo-
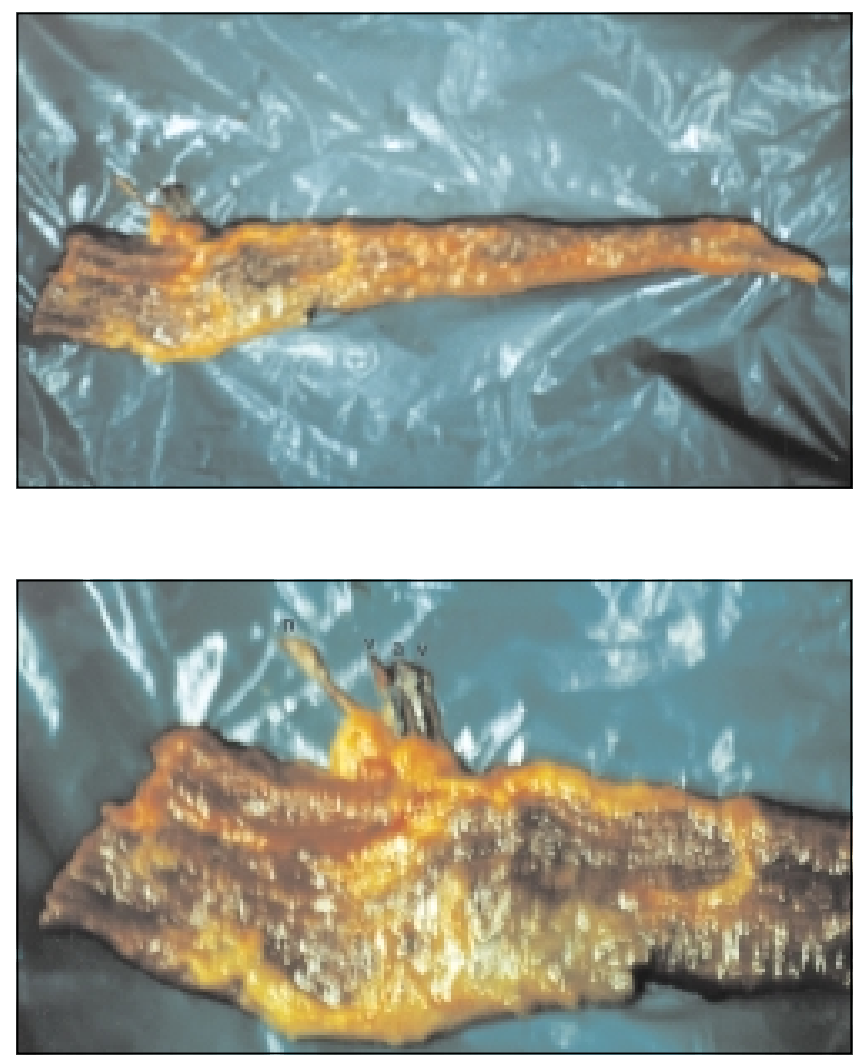

Figure 6) Top The gracilis muscle after complete endoscopic harvesting. Bottom The gracilis muscle with close up view to the vascular pedicle. (a) Main artery; (n) Motor branch of the gracilis muscle; (v) Two venae comitantes

scopic surgical techniques to obtain good and safe results with shorter skin incisions that reduce donor site morbidity following surgery, especially in children.

Although endoscopic dissection is more technically challenging and demanding, skills that are needed to perform this technique can be developed through multiple trials in cadavers and live animal subjects before its clinical application.

ACKNOWLEDGEMENTS: The authors thank Mr Tory Crawford (Snowden-Pencer Corp) for technical assistance with the endoscopic setup.

\section{REFERENCES}

1. Harii K, Ohmori K, Sekiguchi J. The free musculocutaneous flap. Plast Reconstr Surg 1976;57:294-303.

2. Koman LA. Free flaps for coverage of the foot and ankle. Orthopedics 1986;9:857-62.

3. Anthony JP, Mathes SJ, Alpert BS. The muscle flap in the treatment of chronic lower extremity osteomyelitis: results in patients over 5 years after treatment. Plast Reconstr Surg 1991;88:311-8.

4. Yousif NJ, Matloub HS, Kolachalam R, Grunert BK, Sanger JR. The transverse gracilis musculocutaneous flap. Ann Plast Surg 1992;29:482-90.

5. Sobel E, Levitz S. Free gracilis muscle transfer for coverage of severe foot deformities. J Pediatr Orthop 1996;16:388-94.

6. Zukowski M, Lord J, Ash K, Shouse B, Getz S, Robb G. The gracilis free flap revisited: a review of 25 cases of transfer to traumatic extremity wounds. Ann Plast Surg 1998;40:141-4. 
7. Paletz JL, Manketlow RT, Chaban R. The shape of a normal smile: implications for facial paralysis reconstruction. Plast Reconstr Surg 1994;93:784-9.

8. Clark HM, Upton J, Zucker R, Manketlow RM. Pediatric free tissue transfer: an evaluation of 99 cases. Can J Surg 1993;36:525-8.

9. Ueda K, Harii K, Yamada A. Electromyograhic study of functional recovery of free vascularized muscles grafted to the face. Plast Reconstr Surg 1995;95:296-304.

10. Manketlow RT, Zucker RM, Mckee NH. Functioning free muscle transplantation. J Hand Surg Am 1984;(Suppl A):32-7.

11. Whetzel TP, Lechtman A. The gracilis myofasciocutaneous flap: vascular anatomy and clinical application. Plast Reconstr Surg 1997;99:1642-52.

12. Carr MM, Manketlow RT, Zucker RM. Gracilis donor site morbidity. Microsurgery 1995;16:598-600.

13. Deutinger M, Kuzbari R, Paternostro-Sluga T, et al. Donor-site morbidity of the gracilis flap. Plast Reconstr Surg 1995;95:1240-4.

14. Fine NA, Orgill DP, Pribaz JJ. Early clinical experience in endoscopic-assisted muscle flap harvest. Ann Plast Surg 1994;33:465-9.

15. Miller MJ, Robb GL. Endoscopic technique for free flap harvesting. Clin Plast Surg 1995;22:755-73.
16. Saltz R. Endoscopic harvest of the omental and jejunal free flaps. Clin Plast Surg 1995;22:747-54.

17. Rosenberg MH, Sultan MR, Bessler M, Treat MR. Laparoscopic harvesting of jejunal free flaps. Ann Plast Surg 1995;34:250-4.

18. Bass LS, Karp NS, Benacquiesta T, Kasbian AK. Endoscopic harvest of the rectus abdominis free flap: balloon dissection in the fascial plane. Ann Plast Surg 1995;34:274-80.

19. Friedlander L, Sundin J. Minimally invasive harvesting of the latisimus dorsi. Plast Reconstr Surg 1994;94:881-4.

20. Onishi K, Maruyama Y, Yataka M. Endoscopic harvest of the tensor fasciae latae muscle flap. Br J Plast Surg 1997;50:58-60.

21. Doi K, Hattori Y, Soo-Heong T, Hiura Y, Kawakami F. Endoscopic harvesting of the gracilis muscle for reinnervated free-muscle transfer 1997; 100:1817-23.

22. CD Clemente, ed. Gray's Anatomy, 30th American edn. Philadelphia: Lea and Febiger, 1985:294-5.

23. Mathes SJ, Nahai F. Clinical Atlas of Muscle and Musculocutaneous Flaps. St Louis: Mosby, 1979:347-61.

24. Giordano PA, Abbes M, Pequignot JP. Gracilis blood supply: anatomical and clinical re-evaluation. Br J Plast Surg 1990;43:266-72.

25. Erni D, Banic A, Sigurdsson GH. A dynamic study of the circulation in the gracilis muscle in humans. J Reconstr Microsurg 1996;12:515-9. 